Article

\title{
Comparative immunogenicity evaluation of two commonly used infectious bursal disease vaccines in broiler chickens in Ethiopia
}

\author{
Likelesh Legese ${ }^{1}$, Berhane Wakjira $^{1}$, Tsedale Teshome ${ }^{1}$, Dereje Nigussie Woldemichael ${ }^{2}$, Hika Waktole ${ }^{1}$, Fikru Re- \\ gassa $^{1}$, Takele Beyene Tufa ${ }^{1 *}$
}
1 Addis Ababa University College of Veterinary Medicine and Agriculture, Bishoftu, Ethiopia. Email: $\underline{\text { like- }}$ leshlegese@gmail.com (L.L.); berhane.wakjira@aau.edu.et (B.W.); tsedale.teshome@aau.edu.et (T.T.); hika.waktole@aau.edu.et (H.W.); fikruregassa@yahoo.com (F.R.); takele.beyene@aau.edu.et (T.B.T.)
2 Ethiopian Public Health, Institute Vaccine and Diagnostic Production Research, Addis Ababa, Ethiopia dere_nig@hotmail.com (D.N.W.)

*Correspondence: takele.beyene@aau.edu.et ; Tel.: +251911 532131

\begin{abstract}
:
Infectious bursal disease (IBD) is one of the most endemic diseases of commercial poultry in Ethiopia. Vaccination has been practiced as the major means of IBD prevention and control. A study was conducted to determine and compare the immunogenicity of two commercially available IBD vaccines in broiler chicken with maternally derived antibody (MDA). Day-old chickens of 270 were randomly assigned to three groups, group 1 vaccinated with brand 1 vaccine at $7^{\text {th }}$ and $19^{\text {th }}$ days and group 2 with brand 2 vaccine at $15^{\text {th }}$ and $22^{\text {nd }}$ days while group 3 were kept as control. Six chickens were also randomly selected and bled on day 1 for differential leukocyte count (DLC) and determination of MDA. Representative chickens from each group were bled at $24^{\text {th }}$ and $42^{\text {nd }}$ days of age for antibody titration using the indirect ELISA test. DLC scores were determined in the $1^{\text {st }}$ and $24^{\text {th }}$ days. The result revealed highly significant differences $(P=0.001)$ between group 1 and group 2 in DLC at $24^{\text {th }}$ days of age. Antibody titers against IBD were differed significantly $(P=0.02)$ at $24^{\text {th }}$ and $42^{\text {nd }}$ days of age in broilers vaccinated with brand 1 and brand 2 vaccines. It is concluded that although both brands of vaccine induce an adequate immunological response at the end of the experiment, brand 1 vaccine has shown significantly high antibody titers against the IBDV and DLC than brand 2.
\end{abstract}

Keywords: Antibody titer; Broiler chicken; IBD vaccines; Immunogenicity evaluation

\section{Introduction}

The poultry industry is one of the most productive sectors in Ethiopia, which acts as a source of major protein supplements for the growing population of the country. However, disease outbreaks are a major constraint of this industry $[1,2]$.

Infectious bursal disease (IBD), also known as Gumboro, is one of the most important contagious viral diseases of immature chickens in the global poultry industry [3]. The affected chickens have reduced antibody response to vaccinations, strong postvaccinal reactions, and increased susceptibility to concurrent or secondary infections [4]. The disease was first reported in Ethiopia on a farm at Bishoftu in 2002 with high mortality of $50 \%$ in the affected 20-25-day-old broiler and layer chicken [5]. The most economic devastation associated with IBD is due to its immunosuppressive effect that leads to poor vaccination response, secondary bacterial, viral, protozoan infection and poor performance, and poor economic return $[3,6]$. 
The disease is caused by the IBD virus (IBDV) that belongs to the genus Avibirnavirus of the family Birnaviridae with a bi-segmented double-standard (ds) RNA genome $[7,8]$. The virus is highly stable and resistant to many physical and chemical agents and prone to extreme antigenic variability with increased virulence [9]. The clinical signs of infected chickens relate to the age of the chickens and the virulence and the strain of the virus (Rautenschlein et al., 2003). Chickens are more susceptible at 3 to 6 weeks of age and get infected via the fecal-oral route in a direct mode of transmission since the virus is shed in high amounts in feces from 48 hours up to 2 weeks post-infection [10].

There are two distinct serotypes of IBDV. Virus strains belonging to serotype 1 are pathogenic causing disease in young chickens [3] and comprise several pathotypes, such as classical virulent, antigenic variant, and very virulent strains. Serotype 2 viruses are apathogenic for chickens [6]. The classical strain of IBDV belonging to serotype 1 shows the ability to cause clinical disease in infected chickens [11, 12]. In Ethiopia, two genogroups of IBDVs were circulating. Recent genogrouping analysis conducted from Ethiopia by Bari (2021) showed very virulent strains in the country into new sub genogrouping 3. The study confirmed the evidence of Ethiopian isolates in known genogroups and the need of assessing the effectiveness of the available vaccines [13].

The IBDV, like most poultry viruses, has no specific known treatment. Hence, proper prevention and control strategies have been implemented in the poultry industry using proper disinfection and vaccination at the appropriate time [14]. However, extensive usage of live vaccines has resulted in the evolution of new strains [3]. Though a recent study conducted in Ethiopia evaluated the immunogenicity and efficacy of Vero cell-adapted IBDV LC-75 vaccine strain [15], there is no published study that compared the immunogenicity of IBD vaccines available in the local Ethiopian market. Moreover, despite the regular vaccination schedule, there are still frequent reports of IBDV outbreaks in Ethiopia, specifically in Bishoftu town, which could be either of vaccine ineffectiveness or due to a new sub-group of IDBVs circulating in the poultry farms. Therefore, the current study was conducted to determine the level of protection of two IBD vaccination programs in commercial broiler chickens by evaluating the immunogenicity of two commonly used products of the vaccines; one was locally produced and the other was imported from abroad and available on the local market.

\section{Materials and Methods}

\subsection{Study area}

The experimental study was carried out in the poultry houses of the College of Veterinary Medicine and Agriculture, Bishoftu, Ethiopia from February to April 2020. Bishoftu town is found at about $47 \mathrm{~km}$ to the southeast of Addis Ababa and the town where most commercial chicken production farms are available [16].

\subsection{Study population}

A total of 276 broilers of Cobb 500 breeds were purchased for this experiment from Alema Farms PLC, a private large commercial broiler farm located at Bishoftu town, Ethiopia. These broilers were randomly and equally allocated in various experimental groups and were maintained through the duration of the experiments in separate isolation units under the suitable condition for vaccine efficacy tests.

2.3. Housing and management of experimental chickens

In this study, broilers were kept with a floor housing system. The house, feeder, water utensils were thoroughly cleaned, disinfected before stocking broilers. The utensils were also cleaned twice daily to avoid contamination. Thus, the broilers were reared under strict pathogen-free conditions through repeated cleaning and disinfection. Broilers were fed ad libitum on a commercial broiler starter, grower, and finisher diet based on their ages throughout the period of the experiment. A continuous heating program with 200-watt bulbs was suspended at the head height of the broilers. The amount of temperature present in the house was measured and recorded by thermometer and the heat released was adjusted based on the age of chickens from suspended height. 


\subsection{Study design}

The experimental design employed was a stratified randomized controlled trial in the form of follow-up. From a total of 276-day old chickens, six of them were randomly selected and bled on day 1 for differential cell counting and determination of MDA. The rest 270 were randomly assigned to three groups: group 1, group 2, and group 3 with 90 chickens per group and each group with three replicates of 30 chickens per replicate. Group 1 was vaccinated with the recommended dose and as per the schedule of brand 1 vaccine (CEVAC® IBD L) vaccine at $7^{\text {th }}$ and 19th days of age; while group 2 were vaccinated with the recommended dose and schedule of brand 2 vaccine at $15^{\text {th }}$ and $22^{\text {nd }}$ days of age. Group 3 was kept as a control.

\subsection{Study methods}

\section{Vaccination of chicks}

Two types of commercial IBDV vaccines, purchased from the market, were used in this study. The brand 1 vaccine (CEVAC® IBD L, the live freeze-dried vaccine of Winterfield 2512 strain produced by Ceva Sante Animale, France) was purchased from Alema PLC whereas the brand 2 vaccine (Live freeze-dried vaccine of IBDV intermediate standard strain produced by the National Veterinary Institute [NVI), Ethiopia) was purchased directly from the manufacturer. These were live vaccines and administered to chicken as per the manufacturer's directions and given orally by drinking water.

\section{Sample collection and serological test}

On a day old of age, six broilers were randomly selected, and blood collection was performed by incising the jugular vein of broilers and pouring the blood directly into a plain vacutainer tube. At $24^{\text {th }}$ and $42^{\text {nd }}$ days of age, $3 \mathrm{ml}$ of blood samples were collected from ten representative broilers for each group using a disposable $3 \mathrm{ml}$ syringe with a 22gauge needle from the wing vein. Blood samples were centrifuged at $2000 \mathrm{rpm}$ for 10 minutes for separation of sera and sera samples were harvested into cryovials and labelled. Samples were kept at $-20^{\circ} \mathrm{C}$ until laboratory analysis was conducted at the NVI.

\section{Differential leukocyte count}

For differential leukocyte count, thin blood smears were prepared from the blood samples collected at $1^{\text {st }}$ and $24^{\text {th }}$ days of age. The smears were stained by the wrightGiemsa stain. A stained smear was examined to determine the percentage of each type of leukocyte present. Each white cell was recorded on a differential cell counter until 100 white cells were counted. The different types of WBC were expressed as percentages.

Enzyme-linked immunosorbent assay (ELISA) to determine antibodies against IBD vaccine

Antibodies against the IBD vaccine were measured on serums that were collected at a day-old age, at $24^{\text {th }}$ days of age (17 days post-primary immunization and 5 days postsecond immunization for brand 1 vaccine) and (9 days post-primary immunization and 2 days post-second immunization for brand 2 vaccine) and $42^{\text {nd }}$ days age. The mean antibody titer in the sera samples was analyzed to compare the mean titer after IBD vaccinations with the baseline titer and to compare the mean titer among the experimental groups.

According to the instruction of the kit manufacturer IDvet, the indirect enzymelinked immunosorbent assay (ELISA) diagnostic kit was used to detect the antibodies of the chicken directed against the IBD vaccine. Briefly, five hundred-fold (1:500) dilutions were used. About $245 \mu$ l of dilution buffer 14 was added to each well of the microplate. Then $5 \mu \mathrm{l}$ of negative control was added to wells A1 and B1 and $5 \mu 1$ of positive control was added to wells $\mathrm{C} 1$ and D1. After that $5 \mu \mathrm{l}$ of each sample to be tested was added to the remaining wells to make prediluted samples. Then $90 \mu \mathrm{l}$ of dilution buffer 14 and $10 \mu \mathrm{l}$ of the pre-diluted samples were dispersed into the appropriate 96-well plate coated with IBDV viral antigen and the plate was covered and incubated at room temperature for 30 minutes. The plate was washed 3 times with $300 \mu l$ of the wash solution $1 \mathrm{x}$ at the end of the incubation period followed by the addition of horseradish peroxidase conjugate into each well. The plate was allowed to incubate at room temperature for 30 minutes and washed 3 times again before adding $10 \mu \mathrm{l}$ of the substrate solution to each test well which 
was then incubated for 15 minutes at a dark place at room temperature. Finally, 100 $\mu$ l of stop solution was added to each well to stop the reaction and the absorbance was read at $650 \mathrm{~nm}$.

\subsection{Statistical analysis}

The data collected in this study were stored in MS excel and analyzed. The mean antibody titer, standard deviation, and coefficient of variation $(\mathrm{CV}, \%)$ have been calculated by using Microsoft offices excel. Furthermore, STATA version 13 software was also used to analyze the data obtained from the study. Specifically, One-way ANOVA was performed to compare the mean antibody titer of experimental groups. The differences were considered statistically significant at the level of $(\mathrm{p} \leq 0.05)$. The CV $(\%)$ is interpreted as $<30 \%$ Excellent, $30-50 \%$ Good, $51-80 \%$ Fair, and $>90 \%$ Poor response to vaccine. A comparison of DLC values among different groups was analyzed by using linear regression.

\subsection{Ethics statement}

All animal experiments, such as a collection of sera from chickens and immune protection tests of commercial vaccines, were carried out according to protocols approved by the Institutional Review Board of the Addis Ababa University College of Veterinary Medicine and Agriculture and performed following approved animal care guidelines and protocols. The animal ethics committee approval number is VM/ERC/01/13/12/2020.

\section{Results}

\subsection{Antibody measurement}

Maternal antibody titers from the serum samples of chicks showed a wide variation. It ranges from 5040 to 11300 and the average MDA of 1-day-old chickens was $6570 \pm$ 2368.48. Antibody titers against IBDV in broilers vaccinated with brand 1 and brand 2 vaccines showed significant differences between $(\mathrm{p}<0.05)$ group 1 and group 2 on the $24^{\text {th }}$ day of age. There is no antibody detected at this age in the control group. IBDV antibodies in broilers vaccinated with brand 1 and brand 2 vaccines were significantly different $(\mathrm{p}<$ 0.05 ) at $42^{\text {nd }}$ days of age. The coefficient of variation (CV) of group one vaccinated with brand 1 vaccine and group two vaccinated with brand 2 vaccine was 14.39\% and 27.57\% respectively at $42^{\text {nd }}$ days of age. This $\mathrm{CV}$ result of both groups indicates an excellent response to vaccination $(\mathrm{CV}<30 \%)$. As the $\mathrm{CV}$ of group-1 was less than the $\mathrm{CV}$ of group-2, broilers vaccinated with brand 1 vaccine express more excellent response to vaccination (Table 1).

Table 1: Antibodies against IBDV at 24 and 42 days old (Mean \pm standard deviation)

\begin{tabular}{llcc}
\hline Groups & Brands of vaccine & \multicolumn{2}{c}{ Antibody titration at different days } \\
\cline { 3 - 4 } & & $\begin{array}{c}\text { Day 24 } \\
(\text { Mean } \pm \text { SD) }\end{array}$ & Day 42 \\
& & $2475 \pm 148.49$ & (Mean \pm SD) \\
\hline G-1 & Brand 1 & $1250 \pm 353.55$ & $2026 \pm 291.51$ \\
G-2 & Brand 2 & & $1520 \pm 419.11$ \\
G-3 (control) & Non-vaccinated & & \\
\hline
\end{tabular}

G-1, experimental group vaccinated with vaccine brand 1; G-2, experimental group vaccinated with vaccine brand 2; $\mathrm{SD}$, standard deviation

\subsection{Differential leukocyte count}

An experimental trial for comparing the immunogenicity of vaccines in broilers was conducted to evaluate the hematological changes. Differential leukocyte count (DLC) was recorded from six broilers of day-old age and in all experimental groups on $24^{\text {th }}$ days of age from ten representative broilers for each group and a comparison of these values among different groups using linear regression was summarized (Table 2). 
The mean total differential leukocyte count of heterophils, eosinophils, basophils, monocytes and lymphocytes were recorded and analyzed at 24 days of age in all experimental groups. The statistical analysis of lymphocytes showed a highly significant ( $\mathrm{p}<$ 0.01 ) increase in G-1 and G-2 in comparison to the control group (table 4 ). The mean percentage of basophil, eosinophil and monocyte in G-1, G-2 and G-3 revealed a significant increase $(p<0.05)$, but heterophil values revealed a significant decrease $(p<0.05)$ in $G-1$, G-2 and G-3 on 24 days of age (table 2).

Table 2: The linear regression analysis of DLC values in different groups with different days of age

\begin{tabular}{llccccc}
\hline Group & $\begin{array}{c}\text { Age } \\
(\text { day })\end{array}$ & $\begin{array}{c}\text { Heterophils } \\
(\%) \text { Mean } \pm \text { SD }\end{array}$ & $\begin{array}{c}\text { Eosinophils } \\
(\%) \text { Mean } \pm \text { SD }\end{array}$ & $\begin{array}{c}\text { Basophils } \\
(\%) \text { Mean } \pm \text { SD }\end{array}$ & $\begin{array}{c}\text { Monocytes } \\
(\%) \text { Mean } \pm \text { SD }\end{array}$ & $\begin{array}{c}\text { Lymphocytes } \\
(\%) \text { Mean } \pm \text { SD }\end{array}$ \\
\hline Baseline & 01 & $41.5 \pm 1.87$ & $2.67 \pm 0.81$ & $1.0 \pm 0.00$ & $3.67 \pm 0.81$ & $51.17 \pm 2.48$ \\
G-1 $^{*}$ & 24 & $15.9 \pm 1.66$ & $4.9 \pm 0.99$ & $1.3 \pm 0.48$ & $7.4 \pm 1.35$ & $70.5 \pm 2.22$ \\
G-2 $^{* *}$ & 24 & $19.1 \pm 2.47$ & $7.2 \pm 1.99$ & $1.2 \pm 0.63$ & $8.3 \pm 2.41$ & $64.2 \pm 3.39$ \\
Control $^{* * *}$ & 24 & $28.5 \pm 2.07$ & $9.9 \pm 1.37$ & $1.2 \pm 0.63$ & $6.5 \pm 1.58$ & $53.9 \pm 1.97$ \\
\hline
\end{tabular}

G-1* experimental group vaccinated with vaccine brand 1; G-2** experimental group vaccinated with vaccine brand 2; Control $^{* * *}$ unvaccinated group; SD standard deviation

A highly significant increase in the mean lymphocyte count was observed with vaccinated groups in comparison with the control group. This indicates the response of the immune system of broilers to a vaccine.

\section{Discussion}

The timing of broiler vaccination depends on the level of maternal antibody (MDA) present in the chicks [4]. The efficacy of the IBD vaccination program was related to the level of MDA in the chickens. The MDA of chickens can hinder the virus in vaccines infected to the target cells and also reduce the ability of viruses in vaccines to stimulate the chicken's immune system $[17,18]$. Vaccination against IBD in the presence of MDA is not recommended as high levels of MDA at the time of vaccination will neutralize the vaccine virus $[4,17,19]$. This may be the case with some vaccination failures.

In our current study, the baseline antibody titer which was identified from serum sampled from day-old chickens before vaccination was found to be protective. This is because the antibody that comes from the mother is protective until the $18^{\text {th }}$ day [17]. The MDA is of benefit to IBDV infection in chickens at the age of 1-4 weeks [20]. Kreider et al., 1991 divided the ELISA titer of the MDA of chickens into 3 levels: the low level $(<3,000)$, intermediate level $(3,000-5,000)$, and high level $(>6,000)$ [21]. In our experiment, the average MDA of day-old chickens was $6570 \pm 2368.48$ which was categorized in the high level of MDA.

The decay pattern of IBDV- specific MDA proved to be more complex, as it depends largely on initial antibody levels, which may vary within a chicken, making it difficult to predict the optimal time for vaccination [22]. The study revealed that $73.6 \%$ maternal antibody transfer rate [23]. Researchers confirmed that the level of MDA of chicks was below the level of protection between 15-20 days [24] and 15 days [25] and 4-7 days [26] after hatching. However, the use of different types of vaccine and vaccination schedules affects the protection of MDA [24].

The lower baseline antibody titer clearly shows that the level of MDA was minimal. The lower mean antibody titer following the primary vaccination could be due to the younger age of chicken and the low antibody level at baseline. In younger chickens, the immune function is not well developed [27]. After the booster vaccination was given, chicken in both treatment groups had a significantly higher mean antibody titer. 
However, the mean antibody titer was shown to be different among the two treatment groups and the difference observed was statistically significant. At the age of 24 and 42 days, broilers vaccinated with brand 1 vaccine at $7^{\text {th }}$ and $19^{\text {th }}$ days and with brand 2 vaccine at $15^{\text {th }}$ and $22^{\text {nd }}$ days showed significant differences in IBDV antibody $(p<0.05)$.

It was clearly shown that in this study antibody titer of both groups differs significantly. It is further observed that two doses one at day 7 of their age and the other at day 19 of their age of broilers vaccinated with brand 1 vaccine induce protective antibodies against IBDV. Although the brand 1 vaccine is also sensitive to neutralization by MDA, this vaccine may be administered at 7 days of age to protect a chick that may not have a sufficient level of MDA.

Antibody titration of brand 1 vaccine in which the booster dose is given after 12 days of initial dose showed significant differences compared to brand 2 vaccine, which is boosted after 7 days of the initial dose. This result is in line with the study that revealed the booster dose was required after 10-20 days of the initial dose [28]. The initial dose is required for the priming of the vaccine while the booster is required for maximum protection against the antigen. The lack of booster dose results in low antibody titers, resulting in vaccine failure. Furthermore, all chicks were found normal, and no mortality and morbidity were seen for all groups.

In this study, the DLC was found to differ significantly among the treatment groups. Leukocytes have been known to involve in defending the body of animals against various infections. Lymphocytes and monocytes are particularly important cells in defending the body systems against viral infections [27]. The increasing counts of lymphocytes and monocytes in response to vaccination are good evidence for improvement in the immune response of chicken as a result of vaccination. Lymphocytes were known to play a central role in regulating immune response, antibody production, and in effecting cell-mediated immune response [29] while monocytes were known for their role in presenting antigens to lymphocytes and for their final effecter function in clearing intracellular infections [30]. Therefore, the higher lymphocytes and monocytes count in chicken vaccinated with brand 1 and brand 2 vaccines are in line with the observation of higher antibody titer and higher weights of lymphoid organs [31].

A highly significant increase in the mean lymphocyte count was observed with vaccinated groups in comparison with control the group. This indicates the response of the immune system of broilers to vaccines. The higher the lymphocyte number, the more the vaccine was immunogenic. From this result, the brand 1 vaccine was more immunogenic than the brand 2 vaccine, as the mean lymphocyte of group 1 was greater than group 2.

Evaluation of IBDV-vaccine efficacy is difficult in commercial broilers [12]. In Ethiopia, although IBD outbreaks are reported from both broilers and layers farms, efficacy testing is not a well-explored area of science, and therefore still much has to be done to protect the chicken from a disease outbreak. The present study was the first of its kind in Ethiopia and was conducted in experimental settings to compare the immunogenicity of available and commonly used IBD vaccines. The majority of poultry veterinarians and chicken producers in Bishoftu town claimed for good protection of the chicken flock from IBD while using brand 1 (product of Ceva Sante Animale). Our findings may provide valuable information to researchers, poultry veterinarians and producers in devising the time of administration of the vaccines for the prevention of Gumboro disease in Ethiopia. Hence, detailed studies on efficacy testing by challenging the chickens with virulent strains of the virus would suggest the overall protection level of the vaccines.

\section{Conclusions}

The results of the present study indicated that both brands of vaccines induce an adequate positive immunological response at the end of the experiment. Moreover, broilers vaccinated with brand 1 vaccine showed a better immune response to the IBDV vaccination program than brand 2, suggesting the need for a booster dose after 10-20 days of the initial dose. However, a detailed scientific investigation on the vaccination schedule 
should be done as the vaccination schedule was followed as per the manufacturer's recommendations. Further detailed similar studies in layers should also be conducted.

Author Contributions: Conceptualization, T.B.T., F.R., H.W. and D.N.W; methodology, L.L., B.W., and T.B.T.; software, L.L., T.B.T.; validation, T.B.T; formal analysis, L.L.; investigation, L.L, T.B.T., B.W., T.T.; resources, T.B.T.; data curation, L.L and T.B.T.; writing-original draft preparation, L.L.; writing - review and editing, D.N.W., H.W., F.R., and T.B.T.; supervision, T.B.T. and F.R.; project administration, T.B.T.; funding acquisition, T.B.T. All authors have read and agreed to the published version of the manuscript.

Funding: This research was funded by the CEVMed-TR thematic research project of the Addis Ababa University, grant number VPRTT/PY-045/2019.

Institutional Review Board Statement: The study was conducted according to the guidelines of the Declaration of Helsinki, and approved by the Institutional Review Board (or Animals Research Ethics and Review Committee) of the Addis Ababa University College of Veterinary Medicine and Agriculture (VM/ERC/01/13/12/2020).

Informed Consent Statement: Not applicable.

Data Availability Statement: The datasets used and/or analyzed during the current study are available from the corresponding author on reasonable request

Conflicts of Interest: The authors declare no conflict of interest. The funder had no role in the design of the study; in the collection, analyses, or interpretation of data; in the writing of the manuscript, or in the decision to publish the results.

\section{References}

1. Mazengia H. Review on major viral diseases of chickens reported in Ethiopia. J Infect Dis Immun. 2012;4:1-9. doi:10.5897/JIDIx11.001.

2. Sambo E, Bettridge J, Dessie T, Amare A, Habte T, Wigley P, et al. Participatory evaluation of chicken health and production constraints in Ethiopia. Prev Vet Med. 2015;118:117-27.

3. Dey S, Pathak DC, Ramamurthy N, Maity HK, Chellappa MM. Infectious bursal disease virus in chickens: prevalence, impact, and management strategies. Vet Med Res Reports. 2019;10:85-97. doi:10.2147/VMRR.S185159.

4. Butcher GD, Miles RD. Infectious Bursal Disease (Gumboro) in Commercial Broilers. UF/IFAS Extension Ser Vet Med Anim Clin Sci Dep. 2018;VM84:1-3.

5. Zeleke A, Gelaye E, Sori T, Ayelet G, Sirak A, Zekarias B. Investigation on Infectious Bursal Disease Outbreak in Debre Zeit, Ethiopia. Int J Poult Sci. 2005;4:504-6. http://www.oie.int/hs2/ci_. Accessed 12 Oct 2021.

6. van den Berg T, Morales D, Eterradossi N, Rivallan G, D T, R R, et al. Assessment of genetic, antigenic and pathotypic criteria for the characterization of IBDV strains. Avian Pathol. 2004;33:470-6. doi:10.1080/03079450400003650.

7. Mawgod SA, Arafa AS, Hussein HA. Molecular genotyping of the infectious bursal disease virus (IBDV) isolated from Broiler Flocks in Egypt. Int J Vet Sci Med. 2014;2:46-52.

8. OIE. Infectious Bursal Disease (Gumboro disease). OIE Terrestrial Manual. 2018;:931-51. https://www.oie.int/fileadmin/Home/eng/Health_standards/tahm/3.03.12_IBD.pdf. Accessed 17 Oct 2021.

9. Jackwood D, Sommer-Wagner S. Amino acids contributing to antigenic drift in the infectious bursal disease Birnavirus (IBDV). Virology. 2011;409:33-7. doi:10.1016/J.VIROL.2010.09.030.

10. El-Mahdy SS, Farouk H, NA AE-W, MM H. Comparative Studies between Different Types of Live Infectious Bursal Disease (IBD) Vaccine Strains in Egypt. Zagazig Vet J. 2014;42:252-62. doi:10.21608/ZVJZ.2014.60198.

11. Yuan L, Hensley C, Mahsoub HM, Ramesh AK, Zhou P. Infectious bursal disease virus. In: Chapter Two- Microbiota in viral infection and disease in humans and farm animals. Prog Mol Biol Transl Sci. 2020;171:15-60.

12. Rautenschlein S, Kraemer C, Vanmarcke J, Montiel E. Protective efficacy of intermediate and intermediate plus infectious bursal disease virus (IBDV) vaccines against very virulent IBDV in commercial broilers. Avian Dis. 2005;49:231-7. 
13. Bari FD. Genogrouping of Infectious Bursal Disease Viruses Circulating in Ethiopian Chickens: Proposal for Assigning Very Virulent Strains in the Country into New Sub Genogroup 3d. Vet Med Res Reports. 2021;12:43-52. doi:10.2147/VMRR.S296367.

14. Gardin Y, Palya V, Sesti L, Dorsey KM. Efficacy of Infectious Bursal Disease Virus Vaccine Against Various Forms of the Disease. The Poultry Site. 2009. https://www.thepoultrysite.com/articles/efficacy-of-infectious-bursal-disease-virus-vaccine-against-variousforms-of-the-disease. Accessed 12 Oct 2021.

15. Kebede W, Bitew M, Bari FD, Edao BM, Mohammed H, Yami M, et al. Immunogenicity and Efficacy Evaluation of Vero CellAdapted Infectious Bursal Disease Virus LC-75 Vaccine Strain. Vet Med Res Reports. 2021;12:261-70. doi:10.2147/VMRR.S326479.

16. Dessie T, Essatu W, Waaij L Vander, Zegeye F, Gizaw S, van Arendonk J. Village chicken production in the central and western highlands of Ethiopia: Characteristics and strategies for improvement. 2013. https://core.ac.uk/download/pdf/132647171.pdf. Accessed 17 Oct 2021.

17. Besseboua O, Ayad A, Benbarek H. Determination of the optimal time of vaccination against infectious bursal disease virus (Gumboro) in Algeria. Onderstepoort J Vet Res. 2015;82. doi:10.4102/OJVR.V82I1.887.

18. Sarachai C, Chansiripornchai N, Sasipreeyajan J. Efficacy of Infectious Bursal Disease Vaccine in Broiler Chickens Receiving Different Vaccination Programs . Thail J $\quad$ Vet $\quad$ Med. https://www.vet.chula.ac.th/dept/tjvm/full_text/v40/v401/TJVM_40_1_Original1.pdf. Accessed 17 Oct 2021.

19. Lozano F, Gonzalez G, Leorat J, Cazaban C, Sarabia J, Le-Tallec B, et al. Consistency and reliability of the IBD Immune-Complex Vaccine I The Poultry Site. The Poultry Site. 2021. https://www.thepoultrysite.com/articles/consistency-and-reliability-of-the-ibdimmune-complex-vaccine. Accessed 17 Oct 2021.

20. MQ A-N, LA W, YM S, B S-B, LD K. Effect of diffferent levels of maternally derived antibodies on protection against infectious bursal disease virus. Avian Dis. 2004;48:177-82. doi:10.1637/5319.

21. Kreider DL, Skeeles JK, Parsley M, Newberry LA, Story JD. Variability in a commercially available enzyme-linked immunosorbent assay system. II. Laboratory variability. Avian Dis. 1991;35:288-93.

22. Suzuki K, Caballero J, Álvarez F, Faccioli M, Goreti M, Herrero M, et al. Simulation models for estimating optimal vaccination timing for infectious bursal disease in broiler chickens in Paraguay. Int J Poult Sci. 2009;8:559-64.

23. Gharaibeh S, Mahmoud K, Al-Natour M. Field evaluation of maternal antibody transfer to a group of pathogens in meat-type chickens. Poult Sci. 2008;87:1550-5.

24. Alam J, Rahman MM, Sil K, Khan MSR, Sarker M. Effect of Maternally Derived Antibody on Vaccination Against Infectious Bursal Disease (Gumboro) with Live Vaccine in Broiler. Int J Poult Sci. 2012;1:98-101.

25. Michell B, Gomes A, Baião N, Resende M, Lara L, Martins N. Effect of maternally-derived antibodies on the performance and immunity of broilers induced by in ovo or post-hatching immunizations with a live vaccine against infectious bursal disease. Brazilian J Poult Sci. 2009;11:57-63. doi:10.1590/S1516-635X2009000100009.

26. S G, K M. Decay of maternal antibodies in broiler chickens. Poult Sci. 2013;92:2333-6. doi:10.3382/PS.2013-03249.

27. Tizard I. Immunity to viruses. . In: Veterinary Immunology. 10th edition. 2017. https://www.elsevier.com/books/veterinaryimmunology/tizard/978-0-323-52349-3. Accessed 17 Oct 2021.

28. Sharif A, Ahmad T. Preventing Vaccine Failure in Poultry Flocks. Immun - Vaccine Adjuv Deliv Syst Strateg. 2018. doi:10.5772/INTECHOPEN.79330.

29. Hall JE. Unit VI: Blood Cells, Immunity, and Blood Coagulation. In: Guyton and Hall Textbook of Medical Physiology. 13th edition. Philadelphia: ELSEVIER Inc.; 2016. p. 447-76. https://et1lib.org/ireader/2562559. Accessed 17 Oct 2021.

30. Shi C, Pamer EG. Monocyte recruitment during infection and inflammation. Nat Rev Immunol. 11:762. doi:10.1038/NRI3070.

31. Al-Mayah AAS. Immune response of broiler chicks to DL-methionine supplementation at different ages. Int J Poult Sci. 2006;5:169-72. 